\title{
An Embedded Controller Application with Regenerative Braking for the Electric Vehicle
}

\author{
Yusuf Karabacak ${ }^{1}$, Ali Uysal ${ }^{2,}$ * \\ ${ }^{1}$ Land Forces NCO Vocational School, Turkish National Defence University, \\ Cayirhisar, Balikesir, Turkey \\ ${ }^{2}$ Hasan Ferdi Turgutlu Faculty of Technology, Manisa Celal Bayar University, \\ Sehit Ali Karakuzu St. Turgutlu, Manisa, Turkey \\ ali.uysal@cbu.edu.tr
}

\begin{abstract}
Regenerative braking is very important for increasing the total range of an electric vehicle. In this study, an embedded controller, including regenerative braking, is designed and implemented for an electric vehicle. Experimental studies are carried out on an electric vehicle driven by two in-wheel electric motors. In-wheel electric motors are preferred in light electric vehicles, since they are both highly efficient and supports regenerative braking. In our embedded controller application, the in-wheel electric motor is operated in both the motor mode and the regenerative braking mode. The in-wheel electric motor control embedded software is developed in the Matlab/Simulink environment. The developed software is embedded in the DSP STM32F407 microcontroller, which has ARM Cortex-M4 core. The inwheel electric motor is controlled by a fuzzy logic controller in the motor mode, the in-wheel electric motor - in the regenerative braking mode. Different PWM (Pulse Width Modulation) ratios are applied to the wheel electric motor in the regenerative braking mode. The experimental data are recorded in real-time by transferring to a $\mathrm{PC}$ on the electric vehicle. The performance of the study is proven with experimental tests.
\end{abstract}

Index Terms-Electric vehicles; Embedded system; Regenerative braking.

\section{INTRODUCTION}

In a battery-powered electric vehicle, the kinetic energy of the vehicle is converted to chemical energy by regenerative braking. The energy stored in the battery can, then, be reused. Regenerative braking is important to ensure more energy efficiency. There are several studies in the literature related to this subject. The cooperation of regenerative braking and ABS (Anti-lock Braking System) has been discussed in [1], [2]. Regenerative brake control and management strategies have been developed by considering the temperature of the batteries, motor and motor driver, charging current, battery voltage, deceleration, and brake pedal pressure [3]-[8]. For friction braking and optimum energy recovery, regenerative braking is working together in [9]-[13]. Regenerative braking control with electronic stability control and lateral stability control is applied in [14], [15]. Regenerative braking is controlled by

Manuscript received 18 February, 2019; accepted 29 June, 2019.

This study was supported by Karabuk University within the scope of Scientific Research Projects with KBP-BAP-17-YL-044 code. the fuzzy logic controller in [16]-[18]. In an electric vehicle (EV), a controller is designed to increase the energy consumption efficiency by maintaining the balance in steering maneuvers in [20]. Downhill safety assistance is provided to assist the driver of the vehicle in [21]. The PID controller is used to control the task of PWM (Pulse Width Modulation) to maintain the IWEM (In-Wheel Electric Motor) speed during the regenerative braking in [22]. IWEM speed control is controlled by a fuzzy logic controller in [23]-[26]. The subject of this study is different from the literature: Matlab / Simulink based embedded system, fuzzy logic controlled IWEM, the effect of regenerative braking tests on energy recovery, and EV speed at different PWM ratios applied to IWEM.

In this study, an embedded system with regenerative braking for IWEM was designed and implemented. Firstly, the motor drive circuit design with the regenerative braking was implemented. Then, the embedded control system was designed and applied. The embedded system can control the IWEM in both the motor mode and regenerative mode. IWEM motor mode tests were performed at $200 \mathrm{rpm}$, $300 \mathrm{rpm}$, and $400 \mathrm{rpm}$ reference speed on EV. Tests of the $50 \%, 60 \%, 70 \%$, and $75 \%$ PWM switching ratio of the motor driver were performed in the regenerative braking mode. In the conclusion section, speed control performance with fuzzy logic controller in the embedded system of IWEM was discussed. In the tests performed with various PWM ratios in regenerative braking tests, the amount of change in the speed of the EV, the amount of energy transferred to the battery, and the battery voltage changing rates were compared.

\section{MATHEMATICAL EQUATIONS OF AN IN-WHEEL ELECTRIC MOTOR}

Some assumptions are made when creating a mathematical model based on IWEM phase variables. Stator windings are connected to stars. Each winding resistance, self-inductance, and common inductance values are considered constant and equal. The voltages in the windings are in the form of trapezoidal waveforms. The switches on the inverter are considered ideal, and the losses of iron and hysteresis are neglected [19]. Because of these assumptions, the mathematical model of the three-phase IWEM is as in (1): 


$$
\begin{gathered}
{\left[\begin{array}{c}
V_{a} \\
V_{b} \\
V_{c}
\end{array}\right]=\left[\begin{array}{ccc}
R_{a} & 0 & 0 \\
0 & R_{b} & 0 \\
0 & 0 & R_{c}
\end{array}\right]\left[\begin{array}{l}
i_{a} \\
i_{b} \\
i_{c}
\end{array}\right]+} \\
\left.+p\left[\begin{array}{ccc}
L_{a} & L_{a b} & L_{a c} \\
L_{b a} & L_{b} & L_{b c} \\
L_{c a} & L_{c b} & L_{c}
\end{array}\right]\left[\begin{array}{c}
i_{a} \\
i_{b} \\
i_{c}
\end{array}\right]\right]+\left[\begin{array}{c}
e_{a} \\
e_{b} \\
e_{c}
\end{array}\right] .
\end{gathered}
$$

The inductances given in (1) are common inductance and $\mathrm{p}$ is the derivative $(\mathrm{d} / \mathrm{dt})$ operator.

IWEM generally has a surface-mounted rotor and a stator winding with the bulk winding. Because there is no reluctance $(\mathrm{M})$ change in this structure, the values of the inductances (L) remains constant. In addition, when the phase windings are balanced, the resistance values $R_{a}, R_{b}$, and $R_{c}$ are equal ((2)-(4)):

$$
\begin{gathered}
L_{a}=L_{b}=L_{c}=L, \\
L_{a b}=L_{a c}=L_{a b}=L_{b c}=L_{c a}=L_{b c}=L, \\
R_{a}=R_{b}=R_{c}=R,
\end{gathered}
$$

Equation (5) is written by arranging the mathematical model using (2)-(4):

$$
\left[\begin{array}{l}
V_{a} \\
V_{b} \\
V_{c}
\end{array}\right]=\left[\begin{array}{ccc}
R & 0 & 0 \\
0 & R & 0 \\
0 & 0 & R
\end{array}\right]\left[\begin{array}{l}
i_{a} \\
i_{b} \\
i_{c}
\end{array}\right]+p\left[\begin{array}{ccc}
L & M & M \\
M & L & M \\
M & M & L
\end{array}\right]\left[\left[\begin{array}{c}
i_{a} \\
i_{b} \\
i_{c}
\end{array}\right]\right]+\left[\begin{array}{c}
e_{a} \\
e_{b} \\
e_{c}
\end{array}\right] .
$$

The power $\mathrm{P}_{\mathrm{O}}$ generated in the motor shaft is equal to the sum of the $\mathrm{P}_{\mathrm{A}}, \mathrm{P}_{\mathrm{B}}$, and $\mathrm{P}_{\mathrm{C}}$ powers from the phases

$$
P_{O}=P_{A}+P_{B}+P_{C}=e_{a} i_{a}+e_{b} i_{b}+e_{c} i_{c}
$$

The produced electromechanical moment $\mathrm{T}_{\mathrm{e}}$ is:

$$
\begin{gathered}
P_{O}=T_{e} \omega_{m}, \\
T_{e}=\frac{e_{a} i_{a}+e_{b} i_{b}+e_{c} i_{c}}{\omega_{m}},
\end{gathered}
$$

where $\omega_{\mathrm{m}}$ represents the angular velocity of the rotor mechanically. In order to find the electrical angular velocity, the number of poles of the motor must be known. Thus, the electrical angular velocity $\omega_{\mathrm{e}}$, can be found with (9)

$$
\omega_{e}=\frac{P}{2} \omega_{e}
$$

The equation of motion of IWEM is obtained from (10)

$$
T_{e}=J \frac{d_{\omega}}{d t}+B \omega_{m}+T_{L}
$$

where $T_{L}$ is the load torque, $\mathrm{J}$ is the moment of inertia and $\mathrm{B}$ is the coefficient of friction.

\section{OPERATING MODES OF IN-WHEEL ELECTRIC MOTOR}

IWEMs can be used in both motor mode and regenerative braking mode. In IWEM motor mode, it converts electrical energy into mechanical energy. Meanwhile, in mechanical regeneration mode, it converts mechanical energy into electrical energy.

\section{A. Motor Mode}

IWEM is available in various configuration. In this application, a 3-phase motor is used. In the sensor control method, the position of the rotor is determined by 3 Hall effect sensors, which are positioned on the stator. According to the internal structure of IWEM, there are $60^{\circ}$ or $120^{\circ}$ differences between the sensors. Correct phases are switched according to Hall effect sensors. IWEM control is provided by a 6-step algorithm. In each step, two correct phases are selected, and these phases are switched (Table I).

\section{TABLE I. SWITCHING SEQUENCE OF PHASES ACCORDING TO ROTOR POSITION.}

\begin{tabular}{|c|c|c|c|c|c|c|c|c|}
\hline $\begin{array}{c}\text { Deg } \\
\left(\boldsymbol{\theta}_{\mathbf{c}}\right)\end{array}$ & $\begin{array}{c}\text { Phase } \\
\text { A }\end{array}$ & $\begin{array}{c}\text { Phase } \\
\text { B }\end{array}$ & $\begin{array}{c}\text { Chase } \\
\text { C }\end{array}$ & $\begin{array}{c}\text { Hall } \\
\text { A }\end{array}$ & $\begin{array}{c}\text { Hall } \\
\text { B }\end{array}$ & $\begin{array}{c}\text { Hall } \\
\text { C }\end{array}$ & PWM & $\begin{array}{c}\text { Closed } \\
\text { Switch }\end{array}$ \\
\hline $0^{\circ}-60^{\circ}$ & $-\mathrm{Vdc}$ & $\mathrm{Vdc}$ & 0 & 1 & 0 & 0 & B_High & A_Low \\
\hline $60^{\circ}-120^{\circ}$ & 0 & $\mathrm{Vdc}$ & $-\mathrm{Vdc}$ & 1 & 0 & 1 & B_High & C_Low \\
\hline $120^{\circ}-180^{\circ}$ & $\mathrm{Vdc}$ & 0 & $-\mathrm{Vdc}$ & 0 & 0 & 1 & A_High & C_Low \\
\hline $180^{\circ}-240^{\circ}$ & $\mathrm{Vdc}$ & $-\mathrm{Vdc}$ & 0 & 0 & 1 & 1 & A_High & B_Low \\
\hline $240^{\circ}-300^{\circ}$ & 0 & $-\mathrm{Vdc}$ & $\mathrm{Vdc}$ & 0 & 1 & 0 & C_High & B_Low \\
\hline $300^{\circ}-360^{\circ}$ & $-\mathrm{Vdc}$ & 0 & $\mathrm{Vdc}$ & 1 & 1 & 0 & C_High & A_Low \\
\hline
\end{tabular}

Although the brushless DC motors may seem to be powered by a DC supply, the signals are actually AA signals. Therefore, an inverter is used in the brushless DC motor supply. According to the PWM ratio, the level of the voltage to the phases is determined. The phase switches in the motor drive circuit are triggered in sequence, so an $\mathrm{AC}$ signal with a phase difference of 120 degrees between the motor phases is obtained.

\section{B. Regenerative Braking Mode}

Regenerative braking provides more efficient use of the battery by charging the kinetic energy in the vehicle. Regenerative braking can be carried out if the vehicle is moving without gas or is on braking. No voltage is applied to the electric motor during the regenerative braking, but the electric motor charges the battery. In the regenerative braking mode, the switching method is used, in which a single switch is triggered. The PWR signal is applied to the B_L switch in Fig. 1. When the B_L switch is on, the motor current is as in Fig. 1.

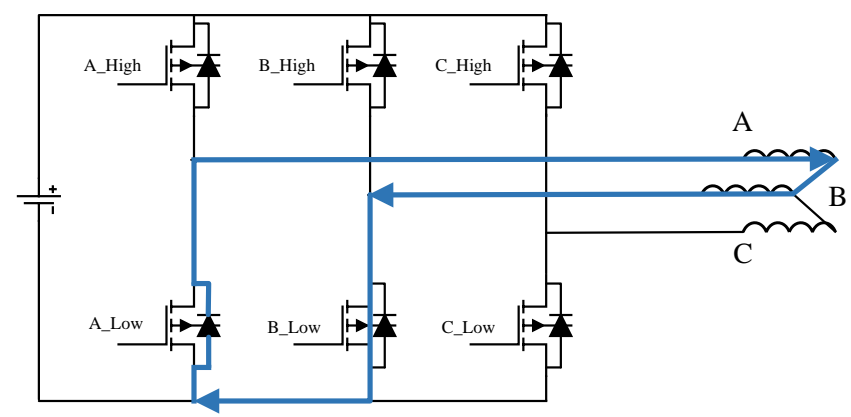

Fig. 1. Motor current when B_low switched on.

If all switches are switched off, the current path induced in the motor is as in Fig. 2. The marked current in Fig. 2 charges the battery.

In regenerative braking, the trigger signal of the power 
switch is determined according to the Hall effect sensors. The switching sequence of the power switches in the regenerative braking is given in Table II.

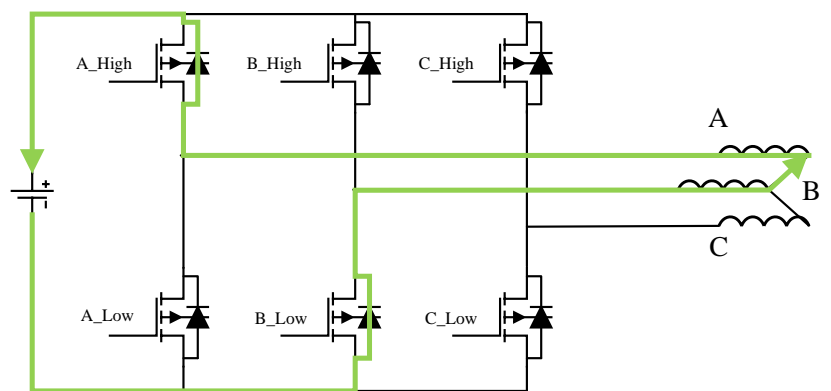

Fig. 2. Motor current when all switches switched off.

TABLE II. THE ORDER OF SWITCHING POWER SWITCHES IN REGENERATIVE BRAKING

\begin{tabular}{|c|c|c|}
\hline Deg $\left(\theta_{e}\right)$ & PWM & Opened Switch \\
\hline $0^{\circ}-60^{\circ}$ & A_Low & A_High, B_High, B_Low C_High, C_Low \\
\hline $60^{\circ}-120^{\circ}$ & C_Low & A_High, A_Low, B_High, B_Low, C_High \\
\hline $120^{\circ}-180^{\circ}$ & C_Low & A_High, A_Low, B_High, B_Low, C_High \\
\hline $180^{\circ}-240^{\circ}$ & B_Low & A_High, A_Low, B_High, C_High, C_Low \\
\hline $240^{\circ}-300^{\circ}$ & B_Low & A_High, A_Low, B_High, C_High, C_Low \\
\hline $300^{\circ}-360^{\circ}$ & A_Low & A_High, B_High, B_Low C_High, C_Low \\
\hline
\end{tabular}

\section{MATERIALS AND METHOD}

The tests of the embedded controller were performed on an EV, which is designed for experimental studies. A picture of this EV is given in Fig. 3.

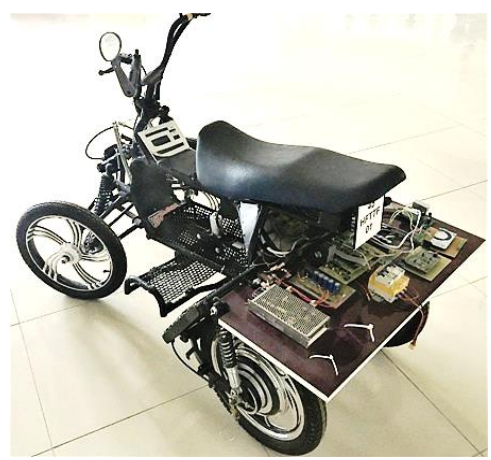

Fig. 3. Electric vehicle.

The block diagram of the Electronic Control System (ECS) for the EV is given in Fig. 4.

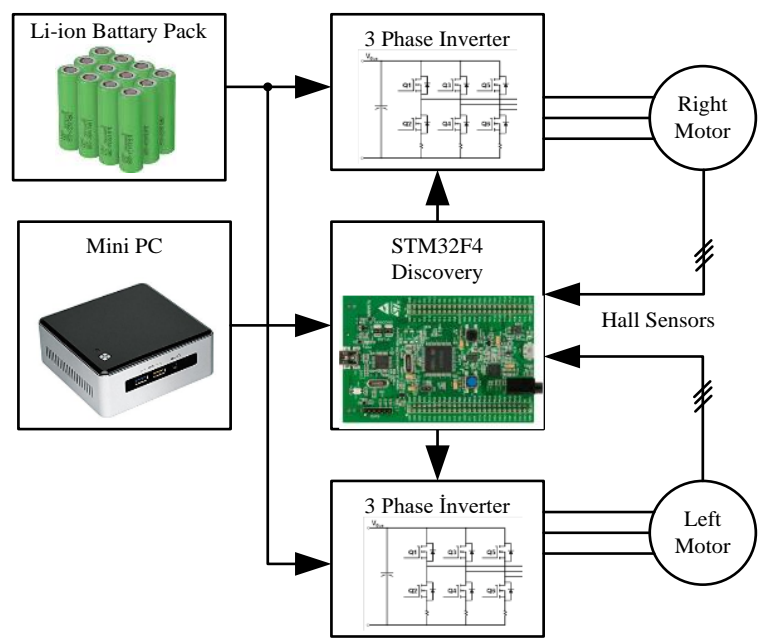

Fig. 4. Electronic control system block diagram.
The EV is driven from the rear by two IWEM. The parameters of IWEMs used in the EV are given in Table III. The STM32F407 Discovery card was used to control the EV.

TABLE III. PARAMETERS OF IWEM.

\begin{tabular}{|c|c|}
\hline Parameter & Value \\
\hline Voltage & $48 \mathrm{~V}$ \\
\hline Nominal Power & $500 \mathrm{~W}$ \\
\hline Maximum Torque & $36.48 \mathrm{Nm}$ \\
\hline Maximum Efficiency & $85.8 \%$ \\
\hline Maximum Revolution & $425 \mathrm{Rpm}$ \\
\hline
\end{tabular}

A Li-ion battery pack is used as a power supply in the EV. This battery pack contains the Panasonic NCR18650B Li-on battery. The batteries are packaged in 3 parallel 13 series patterns. Open circuit voltage of the battery pack is $46.8 \mathrm{~V}$, when the battery is empty. This voltage is $54.6 \mathrm{~V}$, when the battery is full. The total battery capacity of the battery pack is $10.05 \mathrm{Ah}$. The LEM LTS25 current sensor is used to measure the motor current. During testing, the data of the EV (power supply voltage, current, and electric motor speed) are transferred to a mini PC in real-time. Data are recorded in Matlab Simulink environment on a PC.

While IWEM is running in motor mode, the speed control is performed with a fuzzy logic controller. The fuzzy logic controller has two inputs. The first one is speed error, the second - change of the error. The PWM value is calculated for the IWEM driver at the output to the fuzzy logic controller. In this fuzzy logic controller, seven membership functions are used for input and output variables. The membership functions used for input and output variables are given in Fig. 5. The Mamdani's fuzzy inference method is used for the fuzzy logic controller. The rule base used in the fuzzy logic controller is given in Table IV.

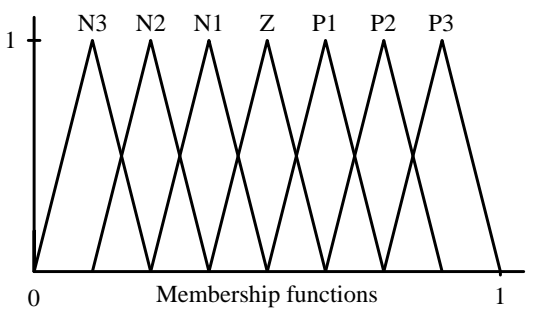

Fig. 5. Inputs and outputs membership functions.

\begin{tabular}{|c|c|c|c|c|c|c|c|}
\hline $\mathbf{e}$ & $\mathbf{N} 3$ & $\mathbf{N 2}$ & $\mathbf{N 1}$ & $\mathbf{Z}$ & $\mathbf{P 1}$ & $\mathbf{P 2}$ & P3 \\
\hline $\mathbf{N 3}$ & N3 & N3 & N3 & N3 & N2 & N1 & Z \\
\hline N2 & N3 & N3 & N3 & N2 & N3 & Z & P1 \\
\hline N1 & N3 & N3 & N2 & N1 & Z & P1 & P2 \\
\hline Z & N3 & N2 & N1 & Z & P1 & P2 & P3 \\
\hline P1 & N2 & N1 & Z & P1 & P2 & P3 & P3 \\
\hline P2 & N1 & Z & P1 & P2 & P3 & P3 & P3 \\
\hline P3 & Z & P1 & P2 & P3 & P3 & P3 & P3 \\
\hline
\end{tabular}

Embedded system software designed for the STM32F407 Discovery card was developed using the Waijung library in the Matlab Simulink environment. The designed embedded system software is shown in Fig. 6. 


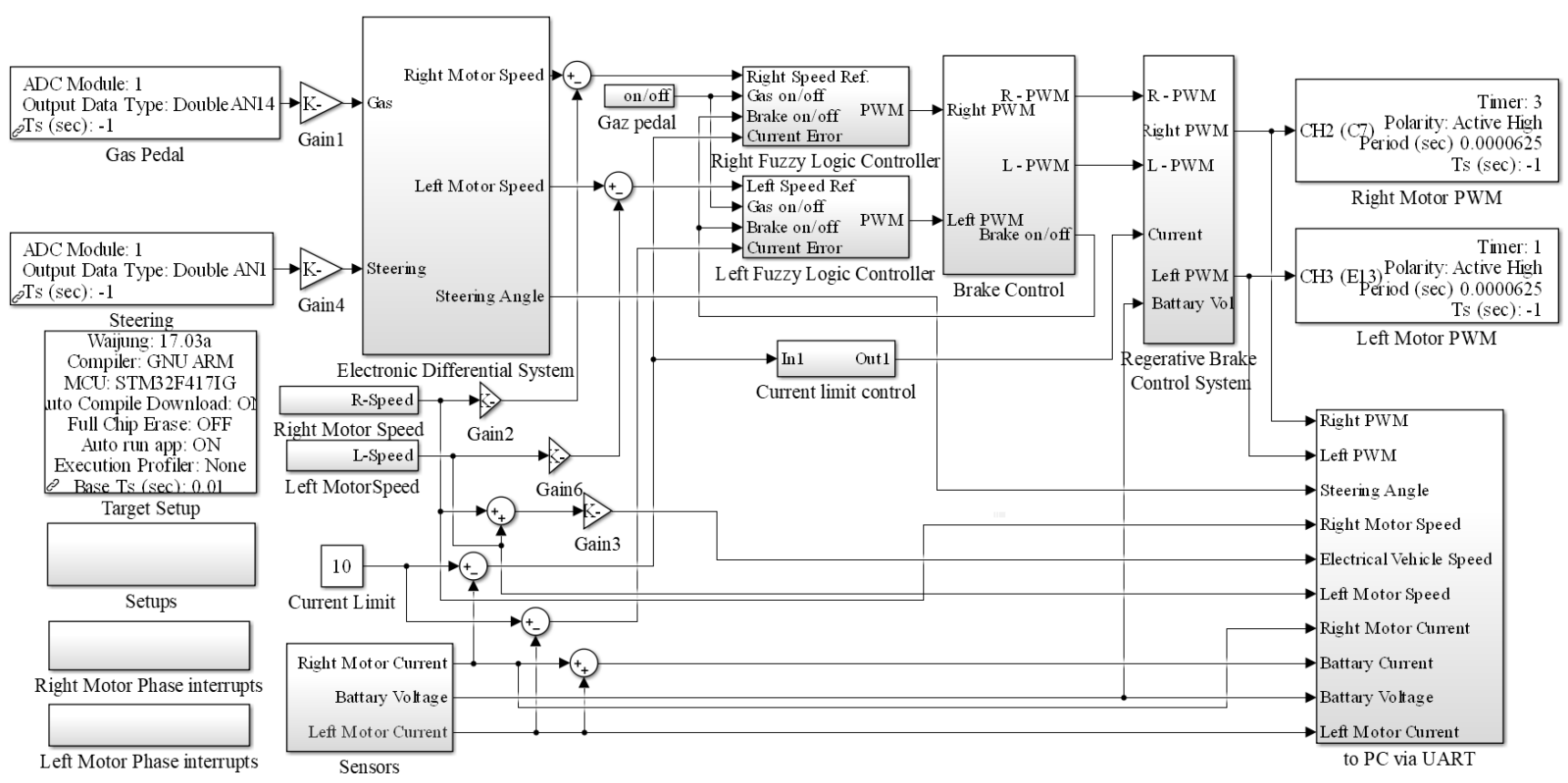

Fig. 6. Matlab/Simulink blocks of electric vehicle embedded system.

The accelerator pedal and steering position data are connected to the DSPs analog-digital input. The speed values of right and left motor are measured by using Halleffect sensors in the motors. In ECS, calculations are made primarily for the Electronic Differential System (EDS). In the EDS, reference speed values are calculated for the right and left motor depending on the accelerator pedal and steering position. Two Fuzzy Logic Control (FLC) blocks at the EDS block output generate a control signal for the right and left motor. In the brake control block, if the EV is braked, the right and left motor control signals are prevented from being transferred to the motor drive and the FLCs are reseted. The left and right motor control signals are, then, applied to the regenerative brake control system. The regenerative brake control system controls the voltage and current limits of the battery and transmits the right and left motor control signals to the motors. The right and left motor phase interrupt blocks are given in Fig. 7.

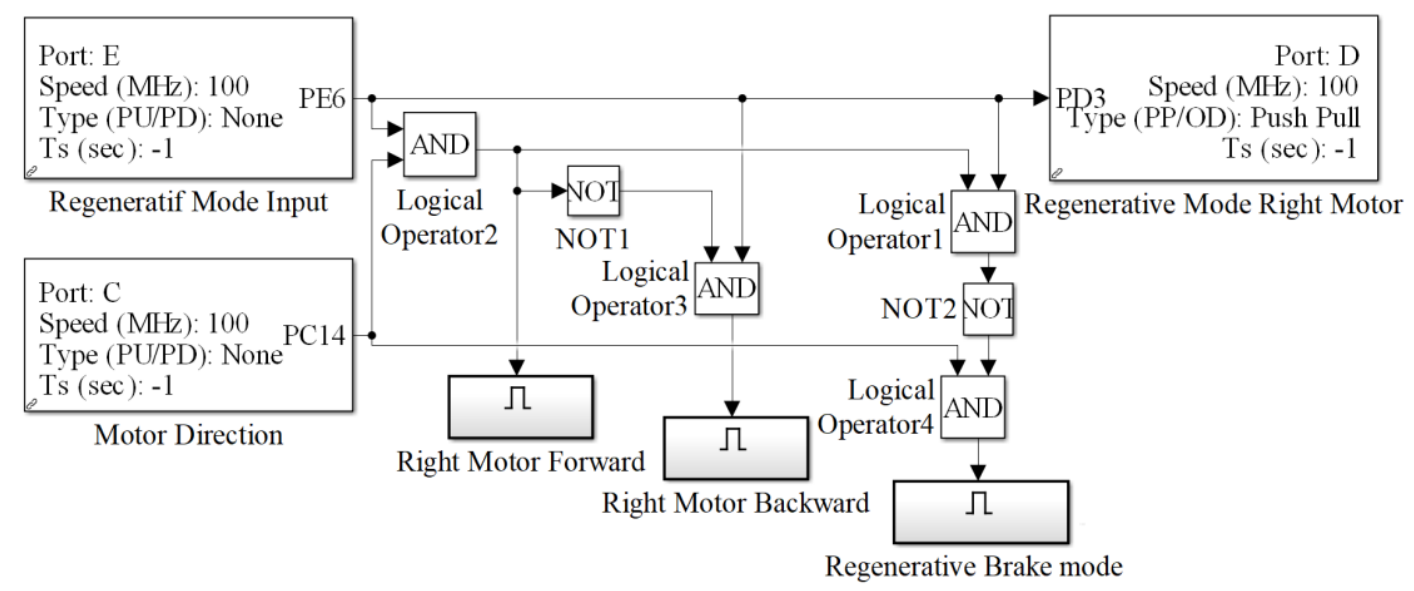

Fig. 7. Motor mode - Regenerative mode control blocks.

The direction is determined for the right and left motor separately, where phase switches will be triggered depending on whether the IWEM is in forward-reverse direction and in the motor mode or in the regenerative braking mode. Hall-effect sensor data of IWEM are used to select phase switches. When IWEM is operating in the regenerative braking mode, the microcontroller generates an interrupt signal, when there is any change in the Hall-effect sensors. When the interrupt occurs, it is determined, which switch in the 3-phase motor drive circuit according to the data in Table II.

\section{RESULTS AND DISCUSSIONS}

The measurement of the experimental data of the designed motor driver circuits was carried out with the Rigol DS1074Z Plus oscilloscope. The drain (D) - source (S) and the gate $(\mathrm{G})$ - source $(\mathrm{S})$ voltages of the upper MOSFET (metal-oxide-semiconductor field-effect transistor) of the IWEM driver, and the current graph of the phase are given in Fig. 8. As shown in Fig. 8, when the MOSFET is switched on, the D-S voltage is zero. When the MOSFET is switched off, it is equal to the power supply voltage between 
the D-S terminals' voltage.

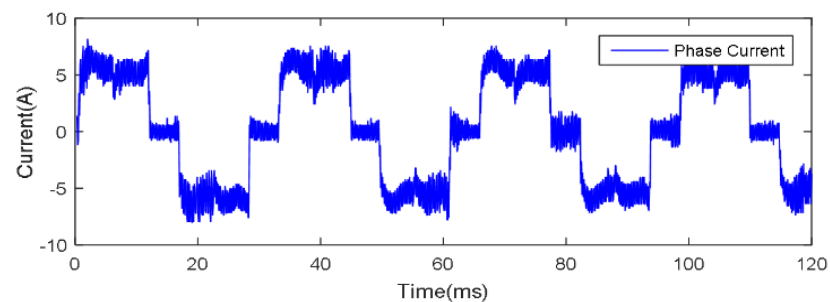

(a)

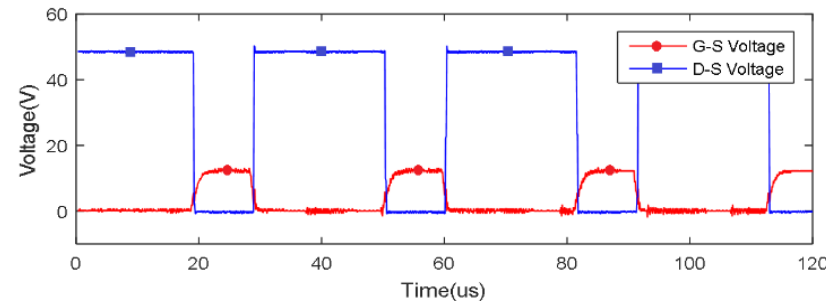

(b)

Fig. 8. Phase current of the motor (a), and D-S, G-S voltages of a halfbridge drive top MOSFET (b).

Phase voltages of the three phases of the motor are given in Fig. 9. In these graphs, phase voltages are obtained as trapezoidal. There is a 120-phase phase difference between each phase.
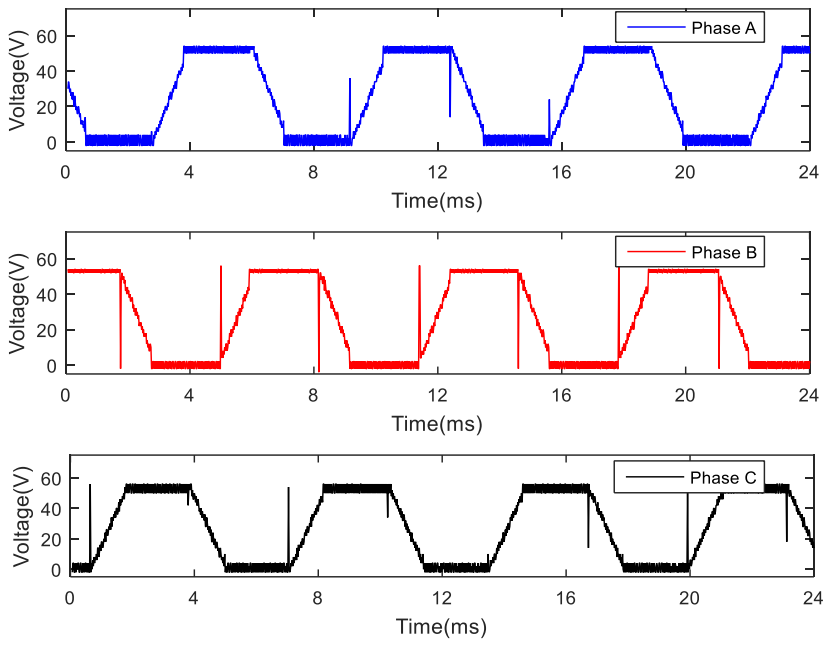

Fig. 9. Phase voltages of the three phases of the motor.

\section{A. Motor Mode Tests with Fuzzy Logic Controller}

As a speed reference value to the fuzzy logic controller is $200 \mathrm{rpm}, 300 \mathrm{rpm}$, and $400 \mathrm{rpm}$, the ramp function is applied. The response of the fuzzy logic controller is analyzed. The response of the system to the reference speed values is given in the graphs of Fig. 10. In the tests carried out at $200 \mathrm{rpm}$ ramp function reference speed, settling time of the motor speed to the reference speed was $2.045 \mathrm{~s}$, average overshoot rate $-0.23 \%$, and average error of the speed $-4.4 \%$. In the tests carried out at $300 \mathrm{rpm}$ ramp function reference speed, settling time of the motor speed to the reference speed was $2.14 \mathrm{~s}$, average overshoot rate $0.21 \%$, and average error of the speed $-2.85 \%$. In the tests carried out at $400 \mathrm{rpm}$ ramp function reference speed, settling time of the motor speed to the reference speed was $2.24 \mathrm{~s}$, average overshoot rate $-0.17 \%$, and average error of the speed $-2.17 \%$.

Measurements showed that the fuzzy logic controller controlled the IWEM at the desired reference values. The fault value of the motor speed following the reference speed during deceleration is caused by the inertia of the motor of the EV.

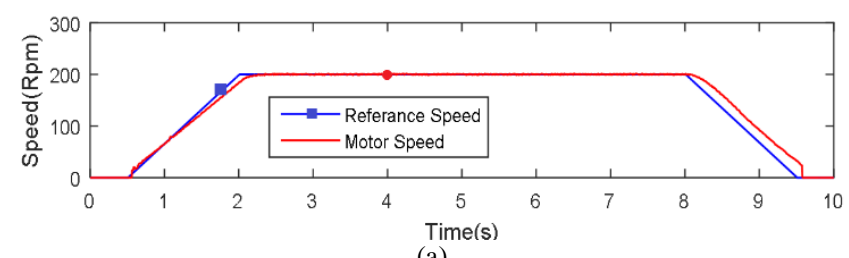

(a)

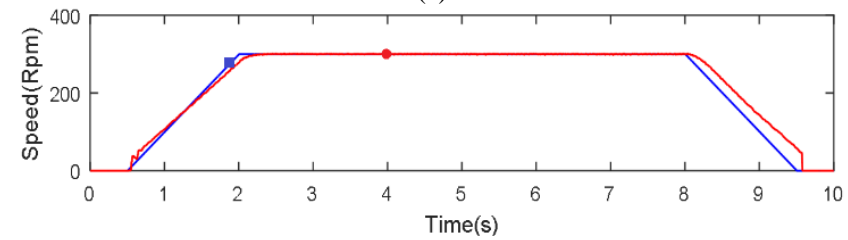

(b)

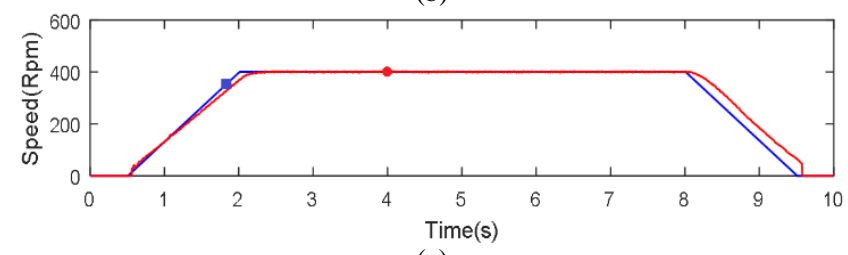

(c)

Fig. 10. Measurements at (a) $200 \mathrm{rpm}$, (b) $300 \mathrm{rpm}$, and (c) $400 \mathrm{rpm}$.

\section{B. Regenerative Mode Tests}

The designed motor drive is tested in a regenerative braking mode at different PWM values on the EV. The data is transferred to the Matlab/Simulink environment in realtime via USB-AMG Converter card. The regenerative braking tests on the EV are made for $10 \mathrm{~s}$, while the IWEM is being run at $400 \mathrm{rpm}$. When IWEM is switched to $50 \%$ PWM with the regenerative braking mode, battery voltage increases by $5 \%$. The charging current is measured as $17 \mathrm{~A}$. The rate of deceleration in vehicle speed is $12,5 \%$. The amount of energy stored in the battery is calculated as 29.16 Wh. Test results with $50 \%$ PWM switching ratio are given in Fig. 11.

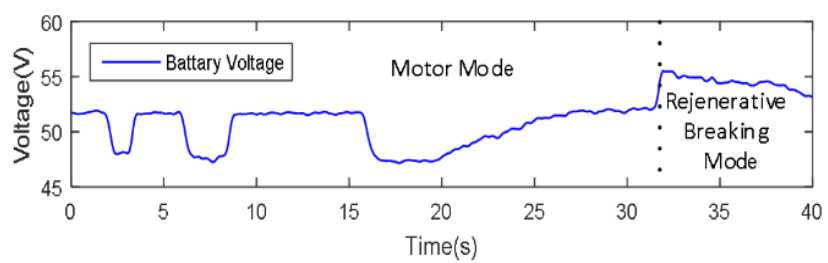

(a)

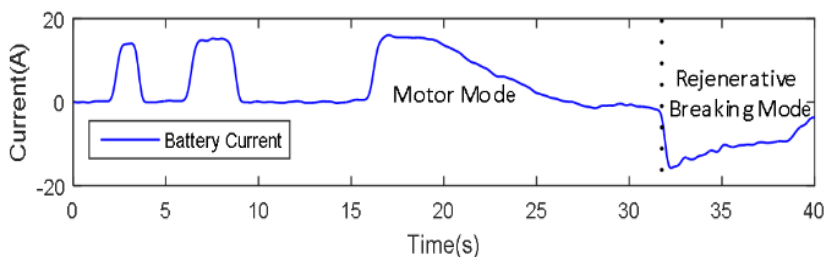

(b)

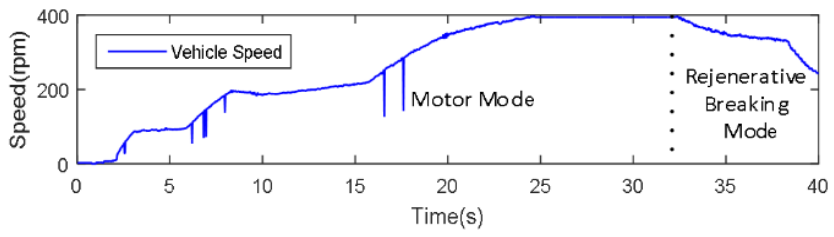

(c)

Fig. 11. Power supply voltage (a), current (b), and IWEM speed (c) when $50 \% \mathrm{PWM}$ value is applied in the regenerative braking mode. 
When IWEM is switched to $60 \%$ PWM with the regenerative braking mode, battery voltage increases by $6 \%$. The charging current is measured as $18 \mathrm{~A}$. The rate of deceleration in vehicle speed is $25 \%$. The amount of energy stored in the battery is calculated as $35.1 \mathrm{Wh}$. Test results with $60 \%$ PWM switching ratio are given in Fig. 12.
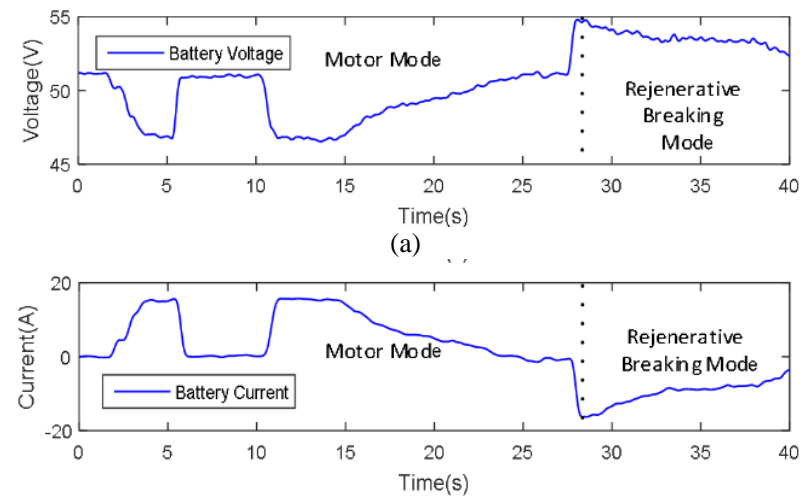

(b)

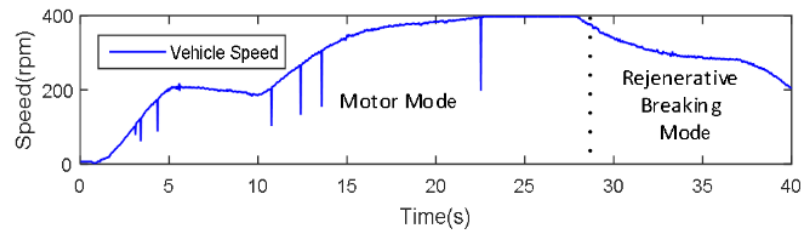

(c)

Fig. 12. Power supply voltage (a), current (b), and IWEM speed (c) when $60 \%$ PWM value is applied in the regenerative braking mode.

When IWEM is switched to $65 \%$ PWM with regenerative braking mode, battery voltage increases by $7 \%$. The charging current is measured as $18 \mathrm{~A}$. The rate of deceleration in vehicle speed is $37,5 \%$. The amount of energy stored in the battery is calculated as $35.1 \mathrm{Wh}$. Test results with $65 \%$ PWM switching ratio are given in Fig. 13.

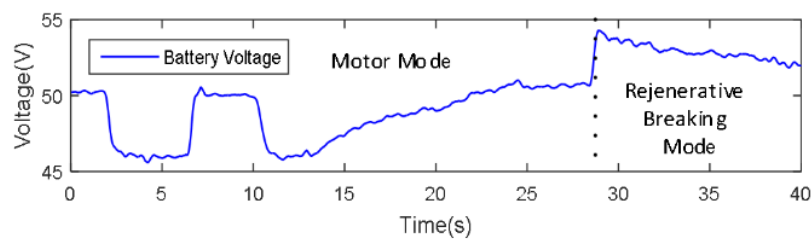

(a)

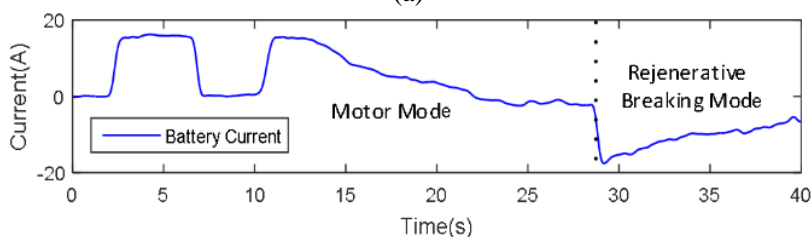

(b)

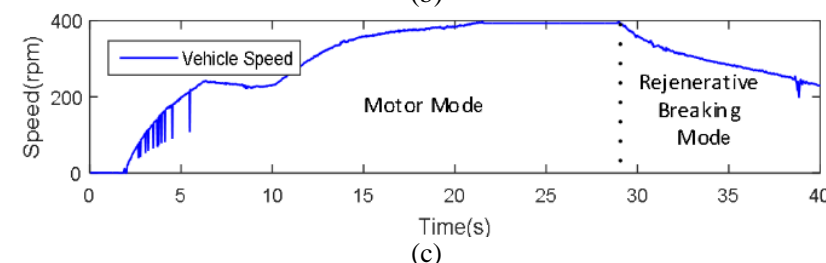

Fig. 13 Power supply voltage (a), current (b), and IWEM speed (c) when $65 \%$ PWM value is applied in the regenerative braking mode.

When IWEM is switched to $70 \%$ PWM with the regenerative braking mode, battery voltage increases by $7,5 \%$. The charging current is measured as $18 \mathrm{~A}$. The rate of deceleration in vehicle speed was $50 \%$. The amount of energy stored in the battery is calculated as $44,82 \mathrm{Wh}$. Test results with $70 \%$ PWM switching ratio are given in Fig. 14.

When IWEM is switched to $75 \%$ PWM with the regenerative braking mode, battery voltage increases by $8,5 \%$. The charging current is measured as $18 \mathrm{~A}$. The rate of deceleration in vehicle speed was $65 \%$. The amount of energy stored in the battery is calculated as 49,68 Wh. Test results with $75 \%$ PWM switching ratio are given in Fig. 15.

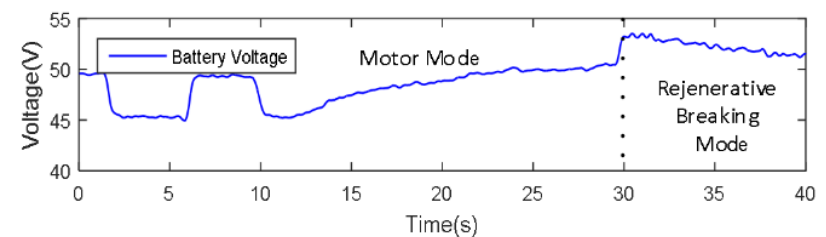

(a)

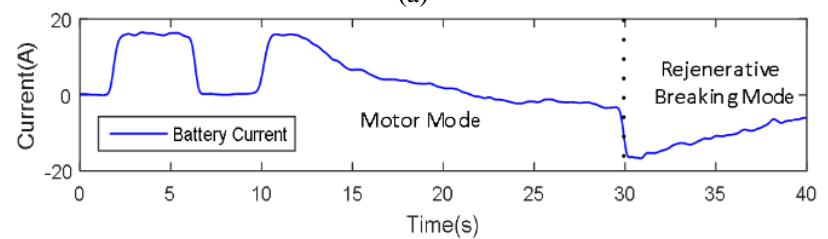

(b)

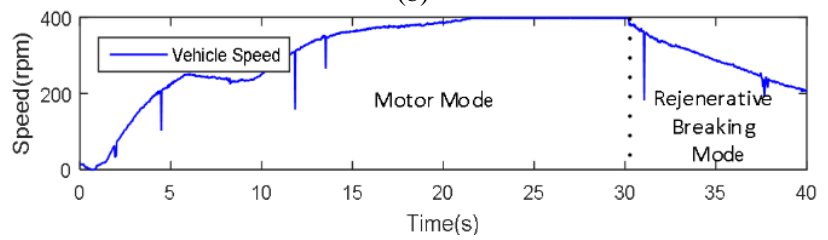

(c)

Fig. 14. Power supply voltage (a), current (b), and IWEM speed (c) when $70 \%$ PWM value is applied in regenerative braking mode.

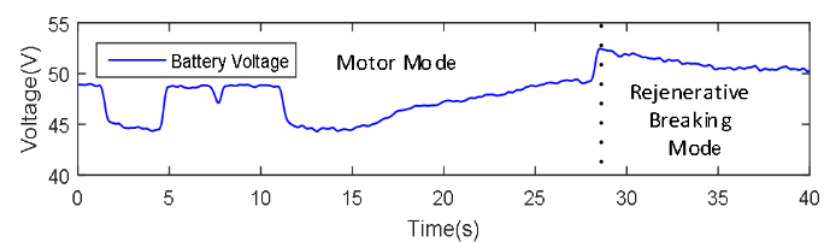

(a)

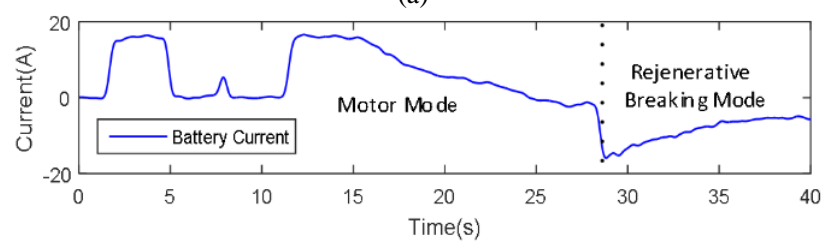

(b)

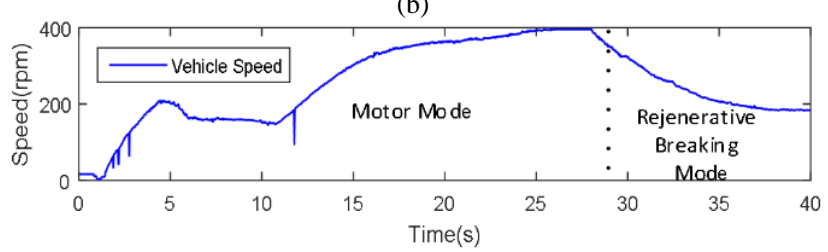

(c)

Fig. 15. Power supply voltage (a), current (b), and IWEM speed (c) when $75 \% \mathrm{PWM}$ value is applied in the regenerative braking mode.

For various PWM values in regenerative braking tests, the rate of increase in the battery voltage, charge current, rate of decrease in vehicle speed, and the amount of energy stored in the battery within $10 \mathrm{~s}$ are given in Table V. When the PWM ratio is increased, the charging voltage of the battery and the battery charging current increase also. Therefore, it is seen that the amount of energy stored in the battery increases in $10 \mathrm{~s}$.

When the PWM value is increased, the decrease in vehicle speed also increases. It is seen that the battery 
charge current is constant after $65 \%$ PWM. This is because the charging current is hardware limited, so that the drive circuit is not damaged by overcurrent. In case of exceeding the specified level, a constant current is ensured.

TABLE V. COMPARISON TABLE FOR REGENERATIVE BRAKING TESTS.

\begin{tabular}{|c|c|c|c|c|c|}
\hline & \multicolumn{5}{|c|}{ PWM Value Applied in Regenerative } \\
\cline { 2 - 6 } & $\begin{array}{c}\text { \% 50 } \\
\text { PWM }\end{array}$ & $\begin{array}{c}\text { \% 60 } \\
\text { PWM }\end{array}$ & $\begin{array}{c}\text { \% 65 } \\
\text { PWM }\end{array}$ & $\begin{array}{c}\text { \% 70 } \\
\text { PWM }\end{array}$ & $\begin{array}{c}\text { \% 75 } \\
\text { PWM }\end{array}$ \\
\hline $\begin{array}{c}\text { Battery Voltage } \\
\text { Change Rate (\%) }\end{array}$ & 5 & 6 & 7 & 7,5 & 8,5 \\
\hline $\begin{array}{c}\text { Maximum Charge } \\
\text { Current of Battery } \\
\text { (A) }\end{array}$ & -17 & -18 & -19 & -19 & -19 \\
\hline $\begin{array}{c}\text { Decrease rate of } \\
\text { Vehicle Speed (\%) }\end{array}$ & 12,5 & 25 & 37,5 & 50 & 65 \\
\hline $\begin{array}{c}\text { Stored Energy to } \\
\text { the Battery in 10 } \\
\text { Seconds (Wh) }\end{array}$ & 29,16 & 35,11 & 39,96 & 44,82 & 49,68 \\
\hline
\end{tabular}

\section{CONCLUSIONS}

In this study, an embedded system application is implemented for use in an EV. The STM32F407 Discovery development board is used as a microcontroller. IWEM is controlled in both motor mode and regenerative braking mode. A fuzzy logic controller is used to control the speed of the IWEM in the embedded system. IWEM Speed control with the fuzzy logic controller is at $200 \mathrm{rpm}, 300 \mathrm{rpm}$, and $400 \mathrm{rpm}$. Various regenerative braking tests are performed by applying various PWM values to the IWEM driver. When the motor speed decreases during regenerative braking, the battery charge current decreases also due to the excitation PWM ratio applied to the motor. The speed of the EV decreases more as the PWM ratio is decreased. The PWM ratio can be used in proportion to the brake pedal in EV's. Regenerative braking test data at the EV are used for the first 10 seconds after the regenerative braking is started. The rate of PWM in the regenerative braking tests is $50 \%$, while the velocity of the EV is $12.5 \%$. Therefore, lower PWM rates are not used. While the rate of PWM is $75 \%$ in regenerative braking tests, the speed of EV decreases by $65 \%$. When the EV velocity graph is examined in Fig. 15, the rate of decrease in the speed of the EV decreases after the start of regenerative braking has dropped below about $200 \mathrm{rpm}$. This indicates that the motor must operate at a speed of at least $200 \mathrm{rpm}$ and above for the regenerative braking to operate efficiently. However, $75 \%$ PWM ratio to the motor drive in regenerative braking mode is the current remaining online in Fig. 1, and $25 \%$ in the current line. The current passing through the A_high and B_low recovery diodes of the power switches is three times more than the current of the battery. Therefore, the current limit values of the recovery diodes of the power switches on the motor drive have a big role.

There are several simulation studies in the literature on the embedded system and regenerative braking issues, but only few of them are application studies. This study is a low-cost real-time controllable application. The accuracy of the system is proven via the measured curves.

\section{CONFLICTS OF INTEREST}

The authors declare that they have no conflicts of interest.

\section{REFERENCES}

[1] W.-P. Chiang, D. Yin, and H. Shimizu, "Slip-based regenerative ABS control for in-wheel-motor drive EV", J. Chinese Inst. Eng., vol. 38, no. 2, pp. 220-231, 2015. DOI: 10.1080/02533839.2014.955974.

[2] L. Li, X. Li, X. Wang, Y. Liu, J. Song, and X. Ran, "Transient switching control strategy from regenerative braking to anti-lock braking with a semi-brake-by-wire system", Veh. Syst. Dyn., vol. 54, no. 2, pp. 231-257, 2016. DOI: 10.1080/00423114.2015.1129059.

[3] J. Huang, D. Qin, and Z. Peng, "Effect of energy-regenerative braking on electric vehicle battery thermal management and control method based on simulation investigation", Energy Convers. Manag., vol. 105, pp. 1157-1165, 2015. DOI: 10.1016/j.enconman.2015.08.080.

[4] L. Li, Y. Zhang, C. Yang, B. Yan, and C. M. Martinez, "Model predictive control-based efficient energy recovery control strategy for regenerative braking system of hybrid electric bus", Energy Convers. Manag., vol. 111, pp. 299-314, 2016. DOI: 10.1016/j.enconman.2015.12.077.

[5] B. Long, S. Lim, Z. Bai, J. Ryu, and K. Chong, "Energy management and control of electric vehicles, using hybrid power source in regenerative braking operation", Energies, vol. 7, no. 7, pp. 43004315, 2014. DOI: 10.3390/en7074300.

[6] S. A. Oleksowicz, K. J. Burnham, A. Southgate, C. McCoy, G. Waite, G. Hardwick, C. Harrington, and R. McMurran, "Regenerative braking strategies, vehicle safety and stability control systems: Critical usecase proposals", Veh. Syst. Dyn., vol. 51, pp. 684-699, 2013. DOI: 10.1080/00423114.2013.767462.

[7] G. Xu, K. Xu, C. Zheng, X. Zhang, and T. Zahid, "Fully electrified regenerative braking control for deep energy recovery and maintaining safety of electric vehicles", IEEE Trans. Veh. Technol., vol. 65, no. 3, pp. 1186-1198, 2016. DOI: 10.1109/TVT.2015.2410694.

[8] G. Xu, W. Li, K. Xu, and Z. Song, "An intelligent regenerative braking strategy for electric vehicles", Energies, vol. 4, no. 9, pp. 1461-1477, 2011. DOI: 10.3390/en4091461.

[9] P. Fajri, S. Lee, V. A. K. Prabhala, and M. Ferdowsi, "Modeling and integration of electric vehicle regenerative and friction braking for motor/dynamometer test bench emulation", IEEE Trans. Veh. Technol., vol. 65, no. 6, pp. 4264-4273, 2016. DOI: 10.1109/TVT.2015.2504363.

[10] J. Ko, S. Ko, H. Son, B. Yoo, J. Cheon, and H. Kim, "Development of brake system and regenerative braking co-operative control algorithm for automatic transmission-based hybrid electric vehicle", IEEE Trans. Veh. Technol., vol. 64, no. 2, pp. 431-440, 2014. DOI: 10.1109/TVT.2014.2325056.

[11] B. Wang, X. Huang, J. Wang, X. Guo, and X. Zhu, "A robust wheel slip ratio control design combining hydraulic and regenerative braking systems for in-wheel-motors-driven electric vehicles", J. Franklin Inst., vol. 352, no. 2, pp. 577-602, 2015. DOI: 10.1016/j.jfranklin.2014.06.004.

[12] M. H. Kwon, J. H. Park, G. S. Gwak, J. W. Huh, H. K. Choi, and H. Hwang, "Cooperative control for friction and regenerative braking systems considering dynamic characteristic and temperature condition", International Journal of Automotive Technology, vol. 17, no. 3, pp. 437-446, 2016. DOI: $10.1007 / \mathrm{s} 12239-016-0045-6$.

[13] L. Li, X. Li, X. Wang, J. Song, K. He, and C. Li, "Analysis of downshift's improvement to energy efficiency of an electric vehicle during regenerative braking", Applied Energy, vol. 176, pp. 125-137, 2016. DOI: 10.1016/j.apenergy.2016.05.042.

[14] L. Zhai, T. Sun, and J. Wang, "Electronic stability control based on motor driving and braking torque distribution for a four in-wheel motor drive electric vehicle", IEEE Trans. Veh. Technol., vol. 65, no. 6, pp. 4726-4739, 2016. DOI: 10.1007/s12239-016-0105-y.

[15] L. Zhai, T. M. Sun, Q. N. Wang, and J. Wang, "Lateral stability control of dynamic steering for dual motor drive high speed tracked vehicle", International Journal of Automotive Technology, vol. 17, no. 6, pp. 1079-1090, 2016. DOI: 10.1007/s12239-016-0105-y.

[16] R. Maia, M. Silva, R. Araujo, and U. Nunes, "Electrical vehicle modeling: A fuzzy logic model for regenerative braking", Expert Syst. Appl., vol. 42, no. 22, pp. 8504-8519, 2015. DOI: 10.1016/j.eswa.2015.07.006.

[17] X. Nian, F. Peng, and H. Zhang, "Regenerative braking system of electric vehicle driven by brushless DC motor", IEEE Trans. Ind. Electron., vol. 61, no. 10, pp. 5798-5808, 2014. DOI: 10.1109/TIE.2014.2300059.

[18] A. Uysal and R. Bayir, "Design and implementation of switched reluctance motor driver for industrial controller", in Proc. of 4th Int. Conf. IEEE Power Engineering, Energy and Electrical Drives (POWERENG 2013), Istanbul, Turkey, 2013, pp. 770-774. DOI: 10.1109/PowerEng.2013.6635707. 
[19] R. Bayir and T. Soylu. "Downhill speed control of in-wheel motor during regenerative braking”, Elektronika Ir Elektrotechnika, vol. 23. no. 6, pp. 40-46, 2017. DOI: 10.5755/j01.eie.23.6.19693.

[20] L. Zhai, R. Hou, T. Sun, and S. Kavuma, "Continuous steering stability control based on an energy-saving torque distribution algorithm for a four in-wheel-motor independent-drive electric vehicle", Energies, vol. 11, no. 2, p. 350, 2018. DOI: 10.3390/en11020350.

[21] Y. Luo, Y. Han, L. Chen, and K. Li, "Downhill safety assistance control for hybrid electric vehicles based on the downhill driver's intention model", in Proc. of the Institution of Mechanical Engineers Part D Journal of Automobile Engineering, vol. 229, no. 13, pp. 1848-1860, 2015. DOI: 10.1177/0954407014567908.

[22] M. Sreejeth, M. Singh, and P. Kumar, "Particle swarm optimisation in efficiency improvement of vector controlled surface mounted permanent magnet synchronous motor drive", IET Power Electronics, vol. 8, no. 5, pp. 760-769, 2015. DOI: 10.1049/iet-pel.2014.0399.

[23] A. Uysal and R. Bayir, "Real-time condition monitoring and fault diagnosis in switched reluctance motors with Kohonen neural network", J. Zhejiang Univ. Sci. C., vol. 14, no. 12, pp. 941-952, 2013. DOI: 10.1631 jzus.C1300085.

[24] E. Soylu and R. Bayir, "Measurement of electrical conditions of rechargeable batteries", Meas. Control, vol. 49, no. 2, pp. 72-81, 2016. DOI: 10.1177/002029401662 9178.

[25] H. Yildiz, A. Uysal, and R. Bayir, "Fuzzy logic control of in-wheel permanent magnet brushless DC motors", in Proc. of 4th Int. Conf. Power Eng. Energy Electr. Drives, 2013, pp. 1142-1146. DOI: 10.1109/PowerEng.2013.6635771.

[26] Y Karabacak and A. Uysal, "Fuzzy logic controlled brushless direct current motor drive design and application for regenerative braking", in Proc. of Artificial Intelligence and Data Processing Symposium (IDAP), 2017, pp. 1-7. DOI: 10.1109/IDAP.2017.8090282. 